\title{
Increased endocannabinoid levels reduce the development of precancerous lesions in the mouse colon
}

\author{
Angelo A. Izzo • Gabriella Aviello • Stefania Petrosino • \\ Pierangelo Orlando • Giovanni Marsicano • Beat Lutz • \\ Francesca Borrelli • Raffaele Capasso • Santosh Nigam • \\ Francesco Capasso • Vincenzo Di Marzo • \\ Endocannabinoid Research Group
}

Received: 18 April 2007 /Revised: 6 July 2007 / Accepted: 10 July 2007 / Published online: 6 September 2007

(C) Springer-Verlag 2007

\begin{abstract}
Colorectal cancer is an increasingly important cause of death in Western countries. Endocannabinoids inhibit colorectal carcinoma cell proliferation in vitro. In this paper, we investigated the involvement of endocannabinoids on the formation of aberrant crypt foci (ACF, earliest preneoplastic lesions) in the colon mouse in vivo. ACF were induced by azoxymethane (AOM); fatty acid amide hydrolase (FAAH) and cannabinoid receptor messenger ribonucleic acid (mRNA) levels were analyzed by
\end{abstract}

Angelo A. Izzo and Gabriella Aviello equally contributed to this work.

Angelo A. Izzo, Gabriella Aviello, Stefania Petrosino, Pierangelo Orlando, Francesca Borrelli, Raffaele Capasso, Francesco Capasso, and Vincenzo Di Marzo are part of the Endocannabinoid Research Group.

A. A. Izzo $(\bowtie) \cdot$ G. Aviello $\cdot$ F. Borrelli $\cdot$ R. Capasso $\cdot$ F. Capasso Department of Experimental Pharmacology,

University of Naples Federico II,

Naples, Italy

e-mail: aaizzo@unina.it

\section{S. Petrosino $\cdot$ V. Di Marzo $(\bowtie)$}

Institute of Biomolecular Chemistry, National Research Council,

Pozzuoli (NA), Italy

e-mail: vdimarzo@icmib.na.cnr.it

\section{S. Petrosino}

Department of Pharmaceutical Sciences, University of Salerno,

Fisciano, Italy

\section{P. Orlando}

Institute of Protein Biochemistry, National Research Council,

Naples, Italy

G. Marsicano $\cdot$ B. Lutz

Molecular Genetics of Behaviour,

Max Planck Institute of Psychiatry,

Munich, Germany

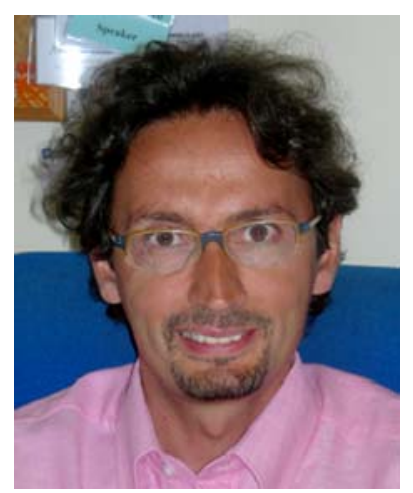

ANGelo A. Izzo

was graduated in Pharmaceutical Chemistry in 1991 and received his Ph.D. in 1995 in Pharmaceutical Sciences at the University of Naples Federico II. He is presently an Associate Professor at the School of Pharmacy

(University of Naples Federico

II). His research interests include the study of the receptors for plant-derived compounds (e.g., cannabinoid, vanilloid, and $\kappa$-opioid receptors) and their role in the physiology and pathophysiology of the digestive tract.

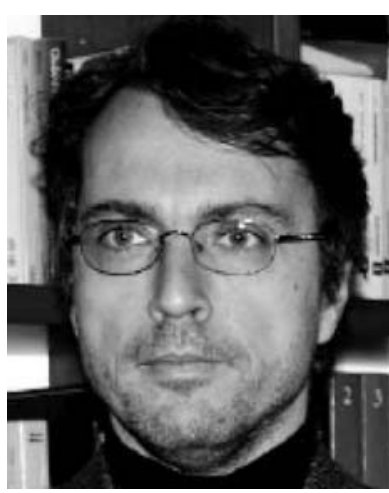

VinCENZO Di MARZo received a degree in Chemistry of the University of Naples and a Ph.D. in biochemistry and molecular pharmacology at the Imperial College, London. He is Research Director at the Institute of Biomolecular Chemistry of the National Research Council in Pozzuoli, Naples, and Coordinator of the Endocannabinoid Research Group in the Naples Region. His research interests include the biosynthesis, metabolism, and physio-pathological role of endocannabinoids and bioactive fatty acid amides. the quantitative reverse transcription polymerase chain reaction (RT-PCR); endocannabinoid levels were measured by liquid chromatography-mass spectrometry; caspase-3 and caspase- 9 expressions were measured by Western blot analysis. Colonic ACF formation after AOM administration was associated with increased levels of 2-arachidonoylglycerol (with no changes in FAAH and cannabinoid receptor 
mRNA levels) and reduction in cleaved caspase- 3 and caspase-9 expression. The FAAH inhibitor $\mathrm{N}$-arachidonoylserotonin increased colon endocannabinoid levels, reduced ACF formation, and partially normalized cleaved caspase- 3 (but not caspase-9) expression. Notably, $N$-arachidonoylserotonin completely prevented the formation of ACF with four or more crypts, which have been show to be best correlated with final tumor incidence. The effect of $N$-arachidonoylserotonin on ACF formation was mimicked by the cannabinoid receptor agonist HU-210. No differences in ACF formation were observed between $\mathrm{CB}_{1}$ receptor-deficient and wild-type mice. It is concluded that pharmacological enhancement of endocannabinoid levels (through inhibition of endocannabinoid hydrolysis) reduces the development of precancerous lesions in the mouse colon. The protective effect appears to involve caspase-3 (but not caspase-9) activation.

Keywords Aberrant crypt foci $\cdot$ 2-arachidonoylglycerol . Cannabinoid receptors $\cdot$ Colon cancer $\cdot$ Fatty acid amide hydrolase (FAAH)

\begin{tabular}{|c|c|}
\hline Abbreviatio & \\
\hline AA-5-HT & $\mathrm{N}$-arachidonoylserotonin, \\
\hline $\mathrm{ACF}$ & aberrant crypt foci, \\
\hline anandamide & arachidonylethanolamide, \\
\hline $\mathrm{AOM}$ & azoxymethane, \\
\hline 2-AG & 2-arachidonylglycerol, \\
\hline DMSO & dimethylsulfoxide; \\
\hline FAAH & fatty acid amide hydrolase, \\
\hline HU-210 & $\begin{array}{l}\text { [(6aR)-trans-3-(1,1-dimethylheptyl)- } \\
\text { 6a,7,10,10a-tetrahydro-1-hydroxy-6,6-di- } \\
\text { methyl-6H-dibenzo }[b, d] \text { pyran-9-methanol], }\end{array}$ \\
\hline RT-PCR & $\begin{array}{l}\text { reverse transcription polymerase chain reac- } \\
\text { tion, }\end{array}$ \\
\hline TRPV1 & transient receptor potential vanilloid type 1 \\
\hline
\end{tabular}

\section{Introduction}

Colon cancer remains a leading cause of death because of cancer in the Western countries; the cumulative lifetime risk of developing colorectal cancer is approximately $5-6 \%$ [1].

G. Marsicano • B. Lutz

Department of Physiological Chemistry,

Johannes Gutenberg-University Mainz,

Mainz, Germany

\section{S. Nigam}

Eicosanoid and Lipid Research Division, Centre for Experimental Gynecology and Breast Research, Free University Berlin, Berlin, Germany
Development of colon cancer is a multistep process involving a series of pathological alterations ranging from discrete microscopic mucosal lesions, like aberrant crypt foci (ACF), to malignant tumors [2]. ACF are early focal lesions of the colonic mucosa composed of one to several enlarged crypts, which are specifically induced by colon carcinogens [3]. Easily identified in methylene blue-stained whole-mount preparations under a dissecting microscope, $\mathrm{ACF}$ are used as early indicators of colon carcinogenesis [1-3].

Cannabinoids have been licensed for clinical use as palliative treatment of chemotherapy, but increasing evidence shows antitumor actions of cannabinoid agonists on several tumor cells in vitro and in animal models $[4,5]$. The main psychotropic cannabinoid is $\Delta^{9}$-tetrahydrocannabinol, which exerts its biological effects mainly by activating two $G$ protein-coupled cannabinoid receptors, named $\mathrm{CB}_{1}$ and $\mathrm{CB}_{2}$ receptors [5]. Endogenous ligands for the cannabinoid receptors have been identified; the best known are arachidonylethanolamide (anandamide) and 2-arachidonoylglycerol (2-AG) [4-6]. When released, anandamide and 2-AG are removed from extracellular compartments by a carrier-mediated reuptake process, and once within the cell, both endocannabinoids are hydrolyzed by intracellular hydrolytic enzymes of which the enzyme fatty acid amide hydrolase (FAAH) is capable of recognizing both compounds as substrates $[5,6]$.

The proposed mechanisms of the antitumoral effect of cannabinoids are complex and may involve induction of apoptosis in tumor cells, antiproliferative actions, and an antimetastatic effects through inhibition of angiogenesis and tumor cell migration [6]. Concerning the gastrointestinal tract, it has been shown that cannabinoid receptor agonists, mostly via $\mathrm{CB}_{1}$ activation, potently inhibit the cell proliferation of colorectal carcinoma cell lines [7]. Furthermore, compounds capable of inhibiting endocannabinoid degradation and hence of prolonging the lifespan of endocannabinoids only when and where these compounds are produced to exert physiological or pathophysiological functions also inhibit colorectal carcinoma growth in vitro [7]. Finally, in a study performed on SW480 colon carcinoma cells, Joseph et al. [8] reported that $\mathrm{CB}_{1}$ activation by anandamide inhibited tumor cell migration, which is of paramount importance in metastasis development. However, the potential antitumoral effect of

S. Nigam

Centre for Experimental Gynecology and Breast Research,

Free University Berlin,

Berlin, Germany

Present address:

G. Marsicano

U 862 Centre de Recherche INSERM François Magendie, Equipe AVENIR 4, 146, rue Léo Saignat,

33077 Bordeaux, France 
cannabinoids, endocannabinoids, and drugs that pharmacologically manipulate endocannabinoid levels and action in the gastrointestinal tract has never been explored in vivo.

Because $\mathrm{CB}_{1}$ receptor activation results in inhibition of colorectal cell proliferation in vitro [7], we investigated here the role of these receptors in the formation of ACF in vivo by using $\mathrm{CB}_{1}$ receptor-deficient mice. In addition, in pharmacological experiments, we also evaluated the effect of drugs that are known to increase endocannabinoid levels in the gastrointestinal tract (i.e., the FAAH inhibitor $N$ arachidonoylserotonin [AA-5-HT] and the endocannabinoid reuptake inhibitor VDM11 [(all Z) N-(2-methyl-3-hydroxyphenyl)-5,8,11,14-eicosa-tetraenamide]), as well as the effect of the ultrapotent cannabinoid $\mathrm{CB}_{1} / \mathrm{CB}_{2}$ receptor agonist, HU-210, on the formation of ACF in the mouse colon in vivo. We also evaluated, by quantitative reverse transcription polymerase chain reaction (RT-PCR), the degree of expression of the messenger ribonucleic acids (mRNAs) encoding for the components of the endogenous cannabinoid system (i.e., $\mathrm{CB}_{1}$ receptor, $\mathrm{CB}_{2}$ receptor, transient receptor potential vanilloid type 1 [TRPV1], FAAH), which have been implicated in cell proliferation and/or apoptosis [4-6]. Finally, because cannabinoids might exert antitumor actions by counteracting caspase activation in tumor cells [4-6], we evaluated the expression of caspase- 3 and caspase- 9 by Western blot analysis. ACF were induced by the genotoxic chemical azoxymethane (AOM) [9].

\section{Materials and methods}

Animals

Experiments were performed on female 5-week-old C57BL/6N mice (Harlan Italy, Corezzana, MI; 20-22 g). In some experiments, female mice lacking the $\mathrm{CB}_{1}$ receptor gene, generated and genotyped as previously described [10], were used. Mutant mice were in a mixed genetic background with a predominance of $\mathrm{C} 57 \mathrm{BL} / 6 \mathrm{~N}$ contribution (five backcrosses for both mutant lines). Mice were fed ad libitum with standard mouse food, except for the 12-h period immediately preceding the killing of the animals. All experiments complied with the Italian D.L. no. 116 of 27 January 1992 and associated guidelines in the European Communities Council Directive of 24 November 1986 (86/609/ECC).

\section{Treatments}

Mice were randomly divided into six groups as follows. Group 1 was treated with vehicles; group 2 was treated with AOM plus the vehicle used to dissolve cannabinoid drugs; group 3 was treated with AOM plus the FAAH inhibitor
AA-5-HT ( $5 \mathrm{mg} / \mathrm{kg}$ ); group 4 was treated with AOM plus the anandamide transporter inhibitor VDM11 (5 mg/kg); group 5 was treated with AOM plus the cannabinoid receptor agonist HU210 ((6aR)-trans-3-(1,1-dimethylheptyl)-6a,7,10,10a-tetrahydro-1-hydroxy-6,6-dimethyl-6Hdibenzo[b,d]pyran-9-methanol; $0.1 \mathrm{mg} / \mathrm{kg})$. In another series of experiments, AOM was given both to wild-type and to $\mathrm{CB}_{1}$ deficient mice. AOM (16 mg/kg in total, IP) was administered during the first ( $3 \mathrm{~m} / \mathrm{kg}$ at days 1 and 5 ), third ( $3 \mathrm{mg} / \mathrm{kg}$ at days 1 and 5$)$, and at the 17 th week $(2 \mathrm{mg} /$ $\mathrm{kg}$ at days 1 and 5) of treatment.

Cannabinoid drugs were given intraperitoneally every other day for the whole duration of the experiment (starting from a week before the first injection of AOM). The doses of cannabinoids were selected on the basis of previous published work dealing with the effects of these drugs in subchronic or chronic experiments [11-13].

All animals were euthanized by asphyxiation with $\mathrm{CO}_{2}$ 6 months after the first injection of AOM. Based on our laboratory experience, this time (at the dose of AOM used) was associated with the occurrence of a significant number of ACF.

\section{Aberrant crypt foci technique}

For ACF determination, the colons were rapidly removed after killing, washed with saline, opened longitudinally, laid flat on a polystyrene board, and fixed with $10 \%$ buffered formaldehyde solution before being stained with $0.2 \%$ methylene blue in saline. The colons were examined using a light microscope at $40 \times$ magnification. Aberrant crypts were identified as previously described [9]. Briefly, in comparison to normal crypts, aberrant crypts have greater size, larger and often elongated openings, thicker lining of epithelial cells, compression of adjacent crypts, and are more darkly stained with methylene blue. According to the number of constituent crypt, ACF were divided into two groups: small ACF containing one to three crypts per focus and large ACF containing four or more crypts per focus. To determine crypt multiplicity, the number of aberrant crypts in each focus was recorded.

Identification and quantification of endocannabinoids and palmitoylethanolamide

Full-thickness colons from control and AOM-treated mice (in the presence or absence of AA-5-HT $5 \mathrm{mg} / \mathrm{kg}$ ) were removed ( 6 months after the first injection of AOM), and tissue specimens were immediately weighed, immersed into liquid nitrogen, and stored at $-70^{\circ} \mathrm{C}$ until extraction of endocannabinoids. Tissues were extracted with chloroform/ 
methanol (2:1, by volume) containing each 200 pmol of $d_{8}$-anandamide, $d_{4}$-palmitoylethanolamide, and $d_{5}$-2-AG, synthesized as described previously (for the former two compounds) [14], or provided by Cayman Chemicals (for $d_{5}$-2-AG, AnnArbor, MI). The lipid extracts were purified by silica column chromatography and carried out as described previously [14], and the fractions containing anandamide, palmitoylethanolamide, and 2-AG were analyzed by isotope dilution liquid chromatography-atmospheric pressure-chemical ionization mass spectrometry carried out in the selected monitoring mode as described in detail elsewhere $[10,14]$. Results were expressed as picomoles or nanomoles per milligram of extracted lipids.

\section{Western blot analysis}

Full-thickness colons from control and AOM-treated (6 months after the first injection of AOM) mice (in the presence or absence of AA-5-HT $5 \mathrm{mg} / \mathrm{kg}$ ) were homogenized in lysis buffer $(1: 2 \mathrm{w} / \mathrm{v})$ containing $0.5 \mathrm{M}$ $\beta$-glycerophosphate, $20 \mathrm{mM} \mathrm{MgCl} 2,10 \mathrm{mM}$ ethylene glycol tetraacetic acid, and supplemented with $100 \mathrm{mM}$ dithiothreitol and protease/phosphatase inhibitors $(100 \mathrm{mM}$ dimethylsulfonyl fluoride, $2 \mathrm{mg} / \mathrm{ml}$ apronitin, $2 \mathrm{mM}$ leupeptin, and $10 \mathrm{mM} \mathrm{Na} \mathrm{VO}_{4}$ ). Homogenates were centrifuged at 3,000 rpm for $5 \mathrm{~min}$ at $4^{\circ} \mathrm{C}$; the supernatants were collected and recentrifuged at $12,000 \mathrm{rpm}$ for $10 \mathrm{~min}$ at $4^{\circ} \mathrm{C}$. Protein concentrations were determined using the method of Bradford [15]. For Western blot analysis, lysate aliquots containing $50 \mu \mathrm{g}$ of proteins were denatured, separated on a $12 \%$ sodium dodecyl sulfate-polyacrylamide gel, and transferred to a nitrocellulose membrane (Amersham, Biosciences, UK) using a Bio-Rad Transblot ( $350 \mathrm{~mA}$ for $3 \mathrm{~h}$ ). Proteins were visualized on the filters by reversible staining with Ponceau-S solution (Sigma, Milan, Italy) and destained in phosphate-buffered saline (PBS). Membranes were blocked at $4^{\circ} \mathrm{C}$ in milk buffer $(5 \%$ nonfat dry milk in PBS $1 \times /$ Tween $0.1 \%$ ) and then incubated overnight at $4{ }^{\circ} \mathrm{C}$ with polyclonal antibodies for caspase-3 and caspase-9 (Calbiochem from VWR International, Italy). The rabbit polyclonal anticaspase-3 and anti-caspase-9 were used at 1:1,000 dilution in milk buffer ( $5 \%$ nonfat dry milk in PBS $1 \times /$ Tween $0.1 \%$ ). Subsequently, the membranes were incubated for $1 \mathrm{~h}$ at room temperature with 1:2,000 anti-rabbit IgG-horseradish peroxidase-conjugated secondary antibodies (Amersham Biosciences, UK). After washing with PBS $1 \times /$ Tween $0.1 \%$, the membranes were analyzed by enhanced chemiluminescence (Amersham Biosciences). The optical density of the bands on autoradiographic films was determined by an image analysis system (GS 700 Imaging Densitometer, BioRad) equipped with a software Molecular Analyst (IBM). After stripping, the membranes were probed with anti- $\alpha$-tubulin antibody, to normalize the results.
Quantitative (real-time) RT PCR analysis

Full-thickness colons from control and AOM-treated (6 months after the first injection of AOM) mice were homogenized in $1 \mathrm{ml}$ of Trizol ${ }^{\circledR}$ (Invitrogen). Total RNA was extracted according to manufacturer recommendations, dissolved in RNA storage solution (Ambion), UV quantified by a Bio-Photometer ${ }^{\circledR}$ (Eppendorf), and stored to $-80^{\circ} \mathrm{C}$. RNA aliquots $(6 \mu \mathrm{g})$ were digested by RNAse-free DNAse I (Ambion deoxyribonucleic acid [DNA]-free ${ }^{\mathrm{TM}}$ kit) in a 20- $\mu$ l final volume reaction mixture, to remove contaminating genomic DNA. After DNAse digestion, concentration and purity of RNA samples were evaluated by the RNA-6000-Nano ${ }^{\circledR}$ microchip assay, using a 2100 Bioanalyzer $^{\circledR}$ equipped with a 2100 -Expert-Software ${ }^{\circledR}$ (Agilent), following the manufacturer instructions. For all samples tested, the RNA integrity number was greater than 6 (relatively to a $0-10$ scale). Three micrograms of total RNA, as evaluated by the 2100 Bioanalyzer, was reverse transcribed in a $25-\mu 1$ reaction mixture containing: $50 \mathrm{mM}$ Tris- $\mathrm{HCl} \mathrm{pH}$ 8.3, $75 \mathrm{mM} \mathrm{KCl}, 3 \mathrm{mM} \mathrm{MgCl}, 10 \mathrm{mM}$ dithiothreitol, $1 \mathrm{mM}$ deoxyribonucleotide triphosphates, $20 \mathrm{U}$ of RNAse inhibitor (Invitrogen), $0.125 \mathrm{~A}_{260}$ units of hexanucleotide mixture (Invitrogen) for random priming and $200 \mathrm{U}$ of MoMuLV Superscript ${ }^{\circledR}$ III reverse transcriptase (Invitrogen). The reaction mixture was incubated in a termocycler $\mathrm{iCycler-i \textrm {Q }}{ }^{\circledR}$ for a $5 \mathrm{~min}$ at a $55^{\circ} \mathrm{C}$ step, followed by a rapid chilling for $2 \mathrm{~min}$ at $4^{\circ} \mathrm{C}$. The protocol was stopped at this step and the MoMuLV reverse transcriptase was added to the samples, excepting the negative controls ( $-\mathrm{RT})$. The incubation was resumed by two thermal steps: $10 \mathrm{~min}$ at $20^{\circ} \mathrm{C}$ followed by $90 \mathrm{~min}$ at $50^{\circ} \mathrm{C}$. Finally, the reaction was terminated by heating at $95^{\circ}$ $\mathrm{C}$ for $10 \mathrm{~min}$. Quantitative real-time PCR was performed by an $\mathrm{iCycler} \mathrm{iQ}{ }^{\circledR}$ in a $25-\mu$ l reaction mixture containing: $1 \times$ iQ-SYBR $^{\circledR}$-Green-Supermix (Bio-Rad), 20 ng of complementary DNA (cDNA; calculated on the basis of the retro-transcribed RNA), and $330 \mathrm{nM}$ for each primer. The amplification profile consisted of an initial denaturation of $2 \mathrm{~min}$ at $94^{\circ} \mathrm{C}$ and 40 cycles of $30 \mathrm{~s}$ at $94^{\circ} \mathrm{C}$, annealing for $30 \mathrm{~s}$ at optimum annealing temperature (TaOpt, see below) and elongation for $45 \mathrm{~s}$ at $68^{\circ} \mathrm{C}$. Fluorescence data were collected during the elongation step. A final extension of 7 min was carried out at $72^{\circ} \mathrm{C}$, followed by melt-curve data analysis. Optimized primers for $\mathrm{SYBR}^{\circledR}{ }^{\circledR}$-Green analysis (and relative TaOpt) were designed by the Beacon-Designer ${ }^{\circledR}$ software 6.0 version (Biosoft International, Palo Alto, CA) and were synthesized (high-performance liquid chromatography purification grade) by MWG-Biotech AG, Germany. Assays were performed in quadruplicate (maximum $\Delta \mathrm{Ct}$ of replicate samples less than 0.5 ), and a standard curve from consecutive fivefold dilutions (100 to $0.16 \mathrm{ng}$ ) of a cDNA pool representative of all samples was included, for PCR 
efficiency determination. Relative expression analysis, correct for PCR efficiency and normalized with respect to reference genes $\beta$-actin and glyceraldehyde-3-phosphate dehydrogenase (GADPH), was performed by GENEX software (Bio-Rad) for groupwise comparison and statistical analysis.

\section{Drugs}

AOM and HU210 were purchased from Sigma and Tocris Cookson (Bristol, UK), respectively. AA-5-HT and VDM11 were synthesized as described previously [16, 17]. All drugs (with the exception of AOM, which was dissolved in saline) were first dissolved in dimethylsulfoxide (DMSO) and then suspended in a lipophilic solution (Peceol/ Gelucire 44/14, gift from Indena, Milan, Italy; $0.4 \%$ DMSO, 96.6\% lipophilic solution). The drug vehicle $(2.5 \mathrm{ml} / \mathrm{kg})$ had no effect on the response under study.

\section{Statistics}

Data are expressed as the mean \pm SEM. To determine statistical significance, analysis of varance followed by the Dunnett's (or Bonferroni's for endocannabinoid levels) test was used.

\section{Results}

\section{Aberrant crypt foci formation}

The total number of $\mathrm{ACF} /$ mouse and number of $\mathrm{ACF} /$ mouse with four or more crypts observed after 6 months of treatment with cannabinoid drugs in either the presence or absence of AOM treatment are shown in Table 1. AOM

Table 1 Effect of cannabinoid drugs (arachidonoylserotonin [AA-5HT, $5 \mathrm{mg} / \mathrm{kg}$ ], VDM11 [5 mg/kg], and HU210 [0.1 mg/kg]) on the formation of aberrant crypt foci (ACF) induced in the mouse colon by azoxymethane (AOM)

\begin{tabular}{lll}
\hline $\begin{array}{l}\text { Treatment } \\
\text { (intraperitoneal) }\end{array}$ & $\begin{array}{l}\text { Number of } \\
\text { ACF/mouse }\end{array}$ & $\begin{array}{l}\text { Number of ACF/mouse } \\
\text { containing } \geq 4 \text { crypts }\end{array}$ \\
\hline Control & 0 & 0 \\
AOM & $12.8 \pm 2.4$ & $0.57 \pm 0.20$ \\
AOM+AA-5HT & $6.3 \pm 1.4^{*}$ & $0^{*}$ \\
AOM+VDM11 & $8.0 \pm 1.08$ & $0.50 \pm 0.29$ \\
AOM+HU210 & $5.1 \pm 1.1^{*}$ & $0^{*}$ \\
\hline
\end{tabular}

$\mathrm{AOM}(16 \mathrm{mg} / \mathrm{kg}$ in total, intraperitoneal) was administered during the first ( $3 \mathrm{mg} / \mathrm{kg}$ at days 1 and 5), third ( $3 \mathrm{mg} / \mathrm{kg}$ at days 1 and 5), and at the 17 th week $(2 \mathrm{mg} / \mathrm{kg}$ at days 1 and 5). Animals were euthanized 6 months after the first injection of AOM. Cannabinoid drugs were given every other day for the whole duration of the experiment. ${ }^{*} p<0.05$ vs AOM ( $n=6-9$ mice for each experimental group)
Table 2 Induction of aberrant crypt foci (ACF) in wild-type and $\mathrm{CB}_{1}$ deficient mice

\begin{tabular}{lll}
\hline $\begin{array}{l}\text { Animal } \\
\text { type }\end{array}$ & $\begin{array}{l}\text { Number of } \\
\text { ACF/mouse }\end{array}$ & $\begin{array}{l}\text { Number of ACF/mouse } \\
\text { containing } \geq 4 \text { crypts }\end{array}$ \\
\hline $\begin{array}{c}\text { Wild-type } \\
\text { mice }\end{array}$ & $14.0 \pm 0.8$ & $2.33 \pm 0.76$ \\
$\begin{array}{c}\mathrm{CB}_{1}-\mathrm{KO} \\
\text { mice }\end{array}$ & $16.5 \pm 1.3$ & $2.33 \pm 0.49$ \\
\hline
\end{tabular}

No significant differences were observed ( $n=6$ for each experimental group). Animals were euthanized 6 months after the first injection of AOM. ACF were induced by AOM $(16 \mathrm{mg} / \mathrm{kg}$ in total, intraperitoneal), which was administered during the first $(3 \mathrm{mg} / \mathrm{kg}$ at days 1 and 5), third (3 mg/kg at days 1 and 5), and at the 17 th week $(2 \mathrm{mg} / \mathrm{kg}$ at days 1 and 5)

given alone induced the appearance of ACF in all the animals. The average number of ACF for each mouse was $12.8 \pm 2.4(0.57 \pm 0.20 \mathrm{ACF}$ with four or more crypts). The FAAH inhibitor AA-5-HT as well as the cannabinoid receptor agonist HU210 significantly reduced the total number of $\mathrm{ACF} / \mathrm{mouse}$ and completely prevented the formation of ACF with four or more crypts in all animals. The anandamide reuptake inhibitor VDM11 showed a nonsignificant trend at reducing the total number of ACF/ mouse and the number of ACF with four or more crypts.

Table 2 shows the result of experiments performed in wild-type and $\mathrm{CB}_{1}$-deficient mice. In this series of experiments, the total number of $\mathrm{ACF} /$ mouse and number of $\mathrm{ACF} /$ mouse with four or more crypts did not change significantly between the two groups of animals.

Endocannabinoid and palmitoylethanolamide content in the colon

Endocannabinoid and palmitoylethanolamide content in full-thickness colons of control and AOM-treated mice is shown in Table 3. AOM treatment significantly increased the levels of 2-AG and induced a nonsignificant trend to increase the levels of anandamide and palmitoylethanolamide. The FAAH inhibitor AA-5-HT further increased 2-AG content and significantly increased anandamide (but not palmitoylethanolamide) levels in AOM-treated mice. A nonsignificant trend to increase anandamide levels was observed also in AOM-treated mice treated with the anandamide cellular reuptake inhibitor VDM11.

Evaluation of $\mathrm{CB}_{1}, \mathrm{CB}_{2}$, FAAH, and TRPV1 mRNA levels by quantitative RT-PCR

The relative expression analysis, evaluated by quantitative RT-PCR, of $\mathrm{CB}_{1}, \mathrm{CB}_{2}$, FAAH, and TRPV1 mRNA in full- 
Table 3 Levels of anandamide, 2-arachidonoylglycerol and palmitoylethanolamide in the mouse colon in control and in azoxymethane (AOM)treated mice

\begin{tabular}{llll}
\hline Treatment & anandamide (pmol/mg lipids) & 2-arachidonoylglycerol (pmol/mg lipids) & palmitoylethanolamide (pmol/mg lipids) \\
\hline Control & $0.9 \pm 0.2$ & $119.8 \pm 20.1$ & $3.1 \pm 0.5$ \\
AOM & $1.6 \pm 0.3$ & $198.2 \pm 29.2^{*}$ & $6.3 \pm 1.8$ \\
AOM+AA-5-HT & $3.4 \pm 0.9 * * * * *$ & $310.9 \pm 53.3^{* * * * * *}$ & $5.0 \pm 1.4$ \\
AOM+VDM11 & $3.0 \pm 0.9$ & $216.0 \pm 80.7$ & $4.9 \pm 2.2$
\end{tabular}

Results are expressed as mean \pm SEM from four to eight animals. AOM $(16 \mathrm{mg} / \mathrm{kg}$ in total, intraperitoneal) was administered during the first $(3 \mathrm{mg} / \mathrm{kg}$ at days 1 and 5), third ( $3 \mathrm{mg} / \mathrm{kg}$ at days 1 and 5), and at the 17 th week (2 mg/kg at days 1 and 5). In some experiments, AOM-treated mice were given the FAAH inhibitor arachidonoylserotonin (AA-5-HT) or the cellular reuptake inhibitor VDM11 (both at the dose of $5 \mathrm{mg} / \mathrm{kg}$ every other day for 6 months). Assay was performed 6 months after the first injection of AOM.

${ }^{*} p<0.05$ and ${ }^{* *} p<0.01$ vs control; ${ }^{* * *} p<0.05 * * * * p<0.01$ vs AOM

thickness colons from AOM-treated mice and controls, is depicted in Fig. 1. All targets were well detectable in the linearity range of analysis $\left(\mathrm{CB}_{1}\right.$, mean cycle threshold $=$ 26.5; $\mathrm{CB}_{2}$, mean cycle threshold $=26$; FAAH, mean cycle threshold $=18$; TRPV1, mean cycle threshold $=30 ; \beta$-actin, mean cycle threshold $=16.5$; GADPH, mean cycle threshold $=$ 24.5). The amplification reaction efficiencies were comparable, ranging from 96 to $108 \%$. Colon samples showed elevated expression (relatively to the other targets and to the housekeeping genes) of FAAH, thus confirming the relevant role of this enzyme in the digestive tract $[18,19]$, although no variation of expression levels in colon samples from AOMtreated mice and controls was observed. Likewise, no variation of $\mathrm{CB}_{1}$ and $\mathrm{CB}_{2}$ expression levels was detected.
On the contrary, a significant decrease (about fourfold) of TPRV1 expression was observed in colon samples of AOMtreated mice.

Expression of activated caspase- 3 and caspase- 9 on colon of AOM-treated mice

AOM significantly $(p<0.001)$ reduced the cleavage of the p34 precursor of caspases- 3 into its p17 active fragment and the $\mathrm{p} 46$ precursor of caspases- 9 into its $\mathrm{p} 34$ active fragment in full-thickness colons (Fig. 2a and b). Treatment with AA-5-HT significantly reduced the effect of AOM on the expression of the activated caspase- 3 but not on the expression of the activated caspases-9 (Fig. 2a and b).

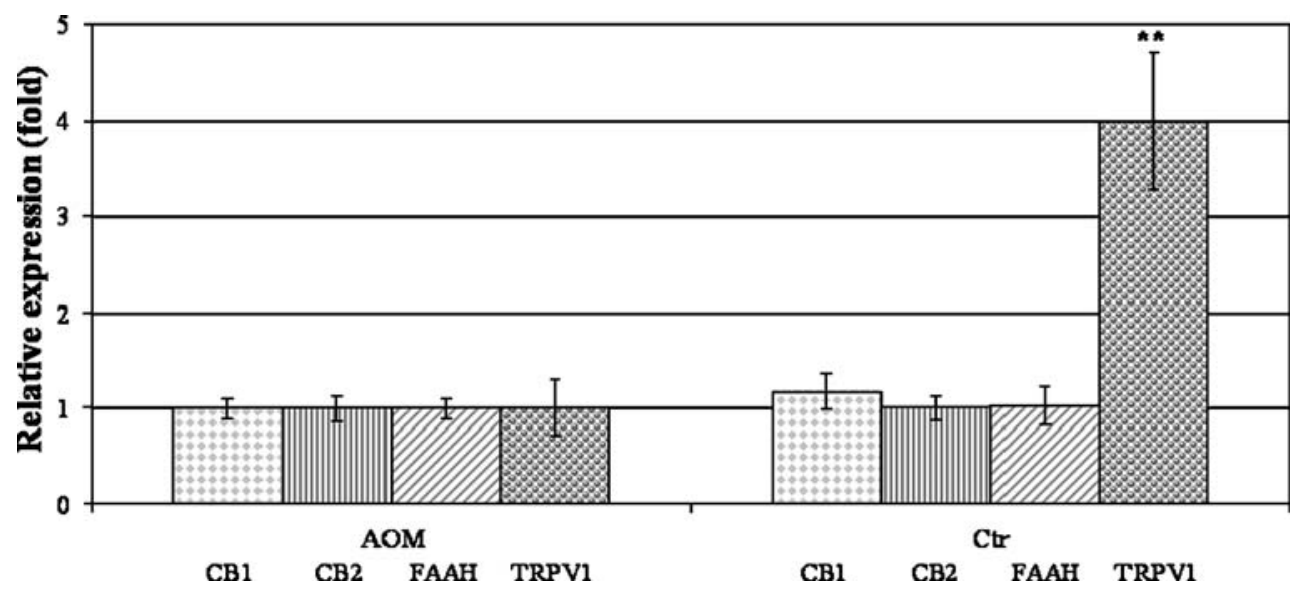

Fig. 1 Relative expression analysis of cannabinoid $C B_{1}$ receptors $\left(C B_{1}\right)$, cannabinoid $\mathrm{CB}_{2}$ receptors $\left(C B_{2}\right)$, fatty acid amide hydrolase $(F A A H)$ and transient receptor potential vanilloid type 1 (TRPVI) in colons of azoxymethane $(A O M)$-treated mice and controls $(C t r)$. The assay was performed 6 months after the first injection of AOM. Total RNA extracted from colons of AOM-treated mice and controls was subjected to quantitative (real-time) RT-PCR analysis as described in the
"Materials and methods." Data were analyzed by GENEX software for groupwise comparisons and statistical analysis. The lowest expression value for each target was considered as 1 . See "Results" for mean cycle thresholds that are indicative of absolute abundance of each target and indicate the following rank of expression in control colons: FAAH $>$ $\mathrm{CB}_{1}=\mathrm{CB}_{2}>$ TRPV1. Double asterisk, $p<0.02$ vs AOM 
Fig. 2 Effect of the FAAH inhibitor arachidonoylserotonin (AA-5-HT) on cleaved caspase-3 (a) and cleaved caspase-9 (b) expression in colon of mice treated with azoxymethane $(A O M)$. The assay was performed 6 months after the first injection of AOM. $A$ Relative expression of cleaved caspases3 (active fragment p17) and caspase-9 (active fragment p34) was quantified by densitometric scanning and normalized by $\alpha$ tubulin. $B$ Representative Western blot analysis. Data are expressed as mean $\pm \mathrm{SE}$ of three independent experiments. Number sign, $p<0.001$ vs control; triple asterisk, $p<0.001 \mathrm{vs}$ $\mathrm{AOM}$ a

B

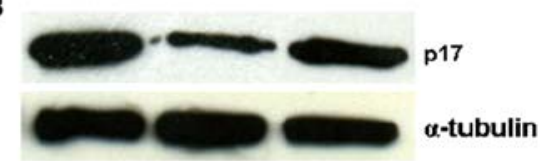

A

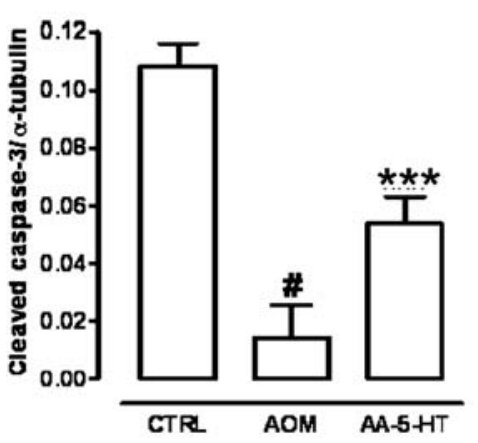

b

B

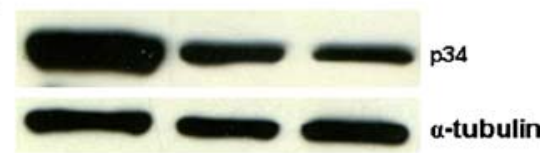

A

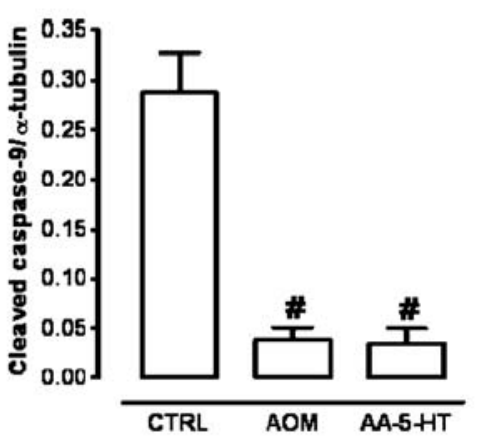

\section{Discussion}

$\mathrm{ACF}$ are believed to be the earliest identifiable neoplastic lesions in the colon carcinogenetic model $[1-3,20]$. They exhibit a number of molecular mutations in regulatory genes consonant with the development of human colon cancer, most notably in the ras oncogene and antigenpresenting cell tumor suppressor gene [20]. In comparison to normal crypts, ACF have greater size, larger and often elongated openings, thicker lining of epithelial cells, compression of adjacent crypts, and are more darkly stained with methylene blue $[1-3,20]$. Recent studies also suggest that ACF are precursors of colon cancer in humans, and this further stimulates the need to identify drugs that may prevent their progression [1-3, 20]. Our findings indicate that the blockade of endocannabinoid enzymatic degradation protects against $\mathrm{ACF}$ formation.

FAAH is a membrane-associated protein responsible of the degradation of endocannabinoids anandamide and 2-AG [21]. Mice lacking FAAH are severely impaired in their ability to degrade anandamide and, when treated with this endocannabinoid, exhibit an array of intense $\mathrm{CB}_{1}$-dependent behavioral responses, including hypomotility, analgesia, catalepsy, and hypothermia [22]. In the digestive tract, FAAH inhibition results in reduction in intestinal motility [23] and anti-inflammatory effects in vivo [12, 24]. Furthermore, FAAH knockout results in lower sensitivity to the proinflammatory agent dinitrobenzene sulfonic acid (DNBS) [12]. The anti-inflammatory role of FAAH is relevant in the light of the observation that inflammation plays an important role in colon carcinogenesis [25]. In this paper, we have shown that a 6-month treatment with AA-5-HT, a selective FAAH inhibitor, strongly reduces the formation of ACF in the mouse colon and completely prevented the number of $\mathrm{ACF}$ with crypt multiplicity of greater than or equal to 4 . The significant reduction in the number of $\mathrm{ACF}$ with four or more crypts is relevant in the light of previous reports in which larger crypts were found to be best correlated with final tumor incidence $[1-3,20]$. We believe that the effect of AA-5-HT is due to FAAH inhibition and not to nonspecific effects or interactions with cannabinoid receptors for the following reasons: (1) AA-5-HT administration increased the levels of anandamide and 2-AG in the colon of mice treated with AOM, similar to that previously observed in the small intestine of healthy mice after acute intraperitoneal administration [23] or in the colon or DNBS-treated mice after repeated intraperitoneal administration [24] with this compound; (2) AA-5-HT displays little or no affinity for cannabinoid receptors [16]; (3) AA-5-HT exerted protective effects in the present study at a dose $(5 \mathrm{mg} / \mathrm{kg})$ previously shown to be inactive in the "open field," "hot plate," and rectal hypothermia tests, which are predictive of $\mathrm{CB}_{1}$ activation in rodents [16]; (4) AA-5-HT was also previously found to be ineffective against anandamide cellular reuptake [16], a mechanism that, however, does not seem to be involved in the control of ACF formation, as VDM11, a selective inhibitor of anandamide cellular uptake, did not significantly affect ACF formation in the present study. The dose of VDM11 used in the present experiments was found to enhance rat hippocampal and mouse brain endocannabinoid levels and to exert neuroprotective effects when administered (intraperitoneally) subchronically every other day (as in our 
experimental conditions) [26]. Consistent with our results, it was previously shown that chronic administration of AA-5-HT (injected intratumor) inhibits the growth of $\mathrm{K}$-ras-transformed rat thyroid cells in athymic mice in vivo [26]. More relevant to our present findings, AA-5-HT was also previously shown to inhibit the proliferation of human colorectal carcinoma cells in vitro in a way attenuated by $\mathrm{CB}_{1}$ receptor blockade, while increasing cell endocannabinoid levels [7]. However, in these two previous studies and unlike our present findings, VDM11 was also found to exert antitumor effects both in vivo (albeit injected intratumor) and in vitro.

The formation of ACF in mice after treatment with $\mathrm{AOM}$ was associated per se to an increase in intestinal 2-AG levels, with a trend toward the increase in anandamide levels too. It should be noted that we performed endocannabinoid assay on full-thickness segments, and thus the cell type responsible of 2-AG overproduction is presently unknown. However, it is likely that these variations reflects changes occurring in mucosal cells, as ACF are located on the mucosa of the intestine [2, 3]. No changes were observed, instead, in the expression of cannabinoid $\mathrm{CB}_{1}$ and $\mathrm{CB}_{2}$ receptors, as assessed by quantitative real-time PCR. This finding is consistent with human studies, which showed increased levels of endocannabinoids but not of cannabinoid receptors, in the mucosa of colorectal adenomatous polyps and carcinomas [7]. It is likely that the enhanced 2-AG levels in the gut exert protective effects on colon carcinogenesis for the following reasons: (1) Pharmacological blockade of endocannabinoid degradation and subsequent elevation of both 2-AG and anandamide levels results in a reduction in preneoplastic lesions (see above); (2) anandamide and 2-AG potently inhibit the proliferation of colorectal carcinoma cells [7]; (3) the protective effect of AA-5-HT on ACF formation observed here was mimicked by the synthetic cannabinoid receptor agonist HU210; we used HU210 rather than endocannabinoids because of its pharmacokinetic properties (i.e., longer half-life of HU210 as opposed to the high metabolic instability of both anandamide and 2-AG). On these bases, we speculate that the administration of AOM in animals increases 2-AG levels, which, in turn, exerts protective effects. A likely target of 2-AG is the cannabinoid $\mathrm{CB}_{2}$ receptor, whose stimulation is known to exert proapoptotic effects [27, 28] and to mediate antiproliferative effects on human colorectal carcinoma cell lines [7]. It is unlikely that 2-AG could act on cannabinoid $\mathrm{CB}_{1}$ receptors to mediate protective effects because in the present study we have observed no statistical differences in $\mathrm{ACF}$ formation between $\mathrm{CB}_{1}$-deficient and wild-type mice. Others have found that systemic or local treatment with cannabinoids inhibited the growth of various types of tumor or tumor cell xenografts in vivo, including lung carcinoma, glioma, thyroid epithelioma, lymphoma, breast carcinoma, and skin carcinoma in mice, via both $\mathrm{CB}_{1}$ - and $\mathrm{CB}_{2}$-mediated pathways as well as through noncannabinoid receptor mechanisms [4-6, 29-30], including cyclooxygenase-2 in colorectal carcinoma cells [31]. It is interesting to note that a recent study showed that chronic oral administration to rats of the antiobesity drug orlistat, which is a very potent inhibitor of 2-AG biosynthesis [32], causes increased formation of ACF in rats [33]. This finding might be interpreted in the light of our present results, by hypothesizing that orlistat, by inhibiting 2-AG formation in the rat colon, might counteract the protection against ACF formation exerted by this endocannabinoid. We did not test the involvement of TRPV1 receptors, which have been proposed as an alternative target for anandamide in the gut under pathological conditions [34], because we found a significant increase only in the levels of 2-AG, which, in contrast to anandamide, does not activate TRPV1 receptors $[5,6]$.

Caspases, a group of cysteine proteases, play an essential role in programmed cell death $[35,36]$. They convey the apoptotic signal in a proteolytic cascade, by cleaving and activating other enzymes that subsequently degrade cellular targets that lead to cell death. The initiator caspases include caspase- 8 and caspase- 9 [35, 36]. Caspase- 8 is activated in response to receptors with a death domain that interacts with the fas-associated death domain (extrinsic pathway), whereas the activation of caspase- 9 is a consequence of cytochrome $c$ and apoptosis-activating factor 1 interaction with AP-1 (intrinsic pathway) $[35,36]$. Both initiators lead to the activation of the final effector caspase-3, which cleaves and inactivates several vital cellular proteins (e.g., DNA repair enzymes) involved in cancer cell life [35, 36]. It has been experimentally demonstrated that during colorectal cancer formation, there is an increased cell proliferation correlated with a reduction in apoposis [37]. In agreement with a reduction in apoptosis in colon cancer [38], we have shown here that AOM treatment reduces the expression of the activated caspase- 3 and caspase- 9 in fullthickness colons. More importantly, treatment with the FAAH inhibitor AA-5-HT partially reversed the AOM effect on caspase-3, suggesting that the activation of this caspase isoform is involved in AA-5-HT-induced inhibition of ACF formation. Therefore, our data allow us to suggest that whatever their exact molecular target(s), pharmacologically elevated endocannabinoids reduce ACF formation via proapoptotic effects. It is very likely that the intrinsic pathway is not involved in these effects, as AA-5-HT did not affect the reduction in expression of activated caspase-9 observed in the colon of AOM-treated animals. In other experimental studies, it has been observed that cannabinoids induce apoptosis in other types of cancer with involvement of extrinsic or intrinsic pathways or both [4-6, 29].

In summary, the present study provides strong evidence that enhancement of colon endocannabinoid levels through 
pharmacological inhibition of their enzymatic hydrolysis may be protective against preneoplastic lesions in the mouse colon; a condition that, like humans adenomatous polyps and colorectal carcinoma [7], is accompanied by an elevated endocannabinoid tone. This protective effect could be due to indirect activation of one or more of the several targets proposed to date for the endocannabinoids and appears to involve caspase-3 activation and subsequent apoptosis of colon preneoplastic cells. Further studies will be required to investigate if cannabinoid $\mathrm{CB}_{2}$ receptors are involved in the protective effects of AA-5-HT and HU210 and if these effects have any therapeutic relevance for the treatment of human colon carcinoma.

Acknowledgments This work was supported by Prin, Enrico and Enrica Sovena Foundation, Regione Campania, Epitech, S.r.l. (to SP and VDM).

Competing interests The Authors declare no competing interests.

\section{References}

1. Kaz AM, Brentnall TA (2003) Genetic testing for colon cancer. Nat Clin Pract Gastroenterol Hepatol 3:670-679

2. Takayama T, Katsuki S, Takahashi Y, Ohi M, Nojiri S, Sakamaki S, Kato J, Kogawa K, Miyake H, Niitsu Y (1998) Aberrant crypt foci of the colon as precursors of adenoma and cancer. N Engl J Med 339:1277-1284

3. Alrawi SJ, Schiff M, Carroll RE, Dayton M, Gibbs JF, Kulavlat M, Tan D, Berman K, Stoler DL, Anderson GR (2006) Aberrant crypt foci. Anticancer Res 26:107-119

4. Bifulco M, Laezza C, Pisanti S, Gazzerro P (2006) Cannabinoids and cancer: pros and cons of an antitumour strategy. $\mathrm{Br} \mathrm{J}$ Pharmacol 148:123-135

5. Di Marzo V, Bifulco M, De Petrocellis L (2004) The endocannabinoid system and its therapeutic exploitation. Nat Rev Drug Discov 3:771-784

6. Pacher P, Batkai S, Kunos G (2006) The endocannabinoid system as an emerging target of pharmacotherapy. Pharmacol Rev 58:389-462

7. Ligresti A, Bisogno T, Matias I, De Petrocellis L, Cascio MG, Cosenza V, D'argenio G, Scaglione G, Bifulco M, Sorrentini I, Di Marzo V (2003) Possible endocannabinoid control of colorectal cancer growth. Gastroenterology 125:677-687

8. Joseph J, Niggemann B, Zaenker KS, Entschladen F (2004) Anandamide is an endogenous inhibitor for the migration of tumor cells and $\mathrm{T}$ lymphocytes. Cancer Immunol Immunother 53:723-728

9. Bartoli R, Fernandez-Banares F, Navarro E, Castella E, Mane J, Alvarez M, Pastor C, Cabre E, Gassull MA (2000) Effect of olive oil on early and late events of colon carcinogenesis in rats: modulation of arachidonic acid metabolism and local prostaglandin E(2)synthesis. Gut 46:191-1999

10. Marsicano G, Wotjak CT, Azad SC, Bisogno T, Rammes G, Cascio MG, Hermann H, Tang J, Hofmann C, Zieglgansberger W, Di Marzo V, Lutz B (2002) The endogenous cannabinoid system controls extinction of aversive memories. Nature 418:530-534
11. Serra S, Carai MA, Brunetti G, Gomez R, Melis S, Vacca G, Colombo G, Gessa GL (2001) The cannabinoid receptor antagonist SR 141716 prevents acquisition of drinking behavior in alcohol-preferring rats. Eur J Pharmacol 430:369-371

12. Massa F, Marsicano G, Hermann H, Cannich A, Krisztina M, Cravatt BF, Ferri G-L, Sibaev A, Storr M, Lutz B (2004) The endogenous cannabinoid system protects against colonic inflammation. J Clin Invest 113:1202-1209

13. van der Stelt M, Mazzola C, Esposito G, Matias I, Petrosino S, De Filippis D, Micale V, Steardo L, Drago F, Iuvone T, Di Marzo V (2006) Endocannabinoids and beta-amyloid-induced neurotoxicity in vivo: effect of pharmacological elevation of endocannabinoid levels. Cell Mol Life Sci 63:1410-1424

14. D’Argenio G, Petrosino S, Gianfrani C, Valenti M, Scaglione G, Grandone I, Nigam S, Sorrentini I, Mazzarella G, Di Marzo V (2007) Overactivity of the intestinal endocannabinoid system in celiac disease and in methotrexate-treated rats. J Mol Med 85:523-530

15. Bradford MM (1976) A rapid and sensitive method for the quantitation of microgram quantities of protein utilizing the principle of protein-dye binding. Anal Biochem 72:248-254

16. Bisogno T, Melck D, De Petrocellis L, Bobrov MYu, Gretskaya NM, Bezuglov VV, Sitachitta N, Gerwick WH, Di Marzo V (1998) Arachidonoylserotonin and other novel inhibitors of fatty acid amide hydrolase. Biochem Biophys Res Commun 248: $515-522$

17. De Petrocellis L, Bisogno T, Davis JB, Pertwee RG, Di Marzo V (2000) Overlap between the ligand recognition properties of the anandamide transporter and the VR1 vanilloid receptor: inhibitors of anandamide uptake with negligible capsaicin-like activity. FEBS Lett 483:52-56

18. Coutts AA, Izzo AA (2004) The gastrointestinal pharmacology of cannabinoids: an update. Curr Opin Pharmacol 4:572-579

19. Massa F, Storr M, Lutz B (2005) The endocannabinoid system in the physiology and pathophysiology of the gastrointestinal tract. J Mol Med 83:944-954

20. Cheng L, Lai MD (2003) Aberrant crypt foci as microscopic precursors of colorectal cancer. World J Gastroenterol 9:2642-2649

21. Ho WS, Hillard CJ (2005) Modulators of endocannabinoid enzymic hydrolysis and membrane transport. Handb Exp Pharmacol 168:187207

22. Cravatt BF, Demarest K, Patricelli MP, Bracey MH, Giang DK, Martin BR, Lichtman AH (2001) Supersensitivity to anandamide and enhanced endogenous cannabinoid signaling in mice lacking fatty acid amide hydrolase. Proc Natl Acad Sci USA 98:9371-9376

23. Capasso R, Matias I, Lutz B, Borrelli F, Capasso F, Marsicano G, Mascolo N, Petrosino S, Monory K, Valenti M, Di Marzo V, Izzo AA (2005) Fatty acid amide hydrolase controls mouse intestinal motility in vivo. Gastroenterology 129:941-951

24. D’Argenio G, Valenti M, Scaglione G, Cosenza V, Sorrentini I, Di Marzo V (2006) Up-regulation of anandamide levels as an endogenous mechanism and a pharmacological strategy to limit colon inflammation. FASEB J 20:568-570

25. Itzkowitz SH, Yio X (2004) Inflammation and cancer. IV. Colorectal cancer in inflammatory bowel disease: the role of inflammation. Am J Physiol Gastrointest Liver Physiol 287:G7-G17

26. Bifulco M, Laezza C, Valenti M, Ligresti A, Portella G, DI Marzo V (2004) A new strategy to block tumor growth by inhibiting endocannabinoid inactivation. FASEB J 18:1606-1608

27. Sanchez C, de Ceballos ML, del Pulgar TG, Rueda D, Corbacho C, Velasco G, Galve-Roperh I, Huffman JW, Ramon y Cajal S, Guzman M (2001) Inhibition of glioma growth in vivo by selective activation of the $\mathrm{CB}(2)$ cannabinoid receptor. Cancer Res 61:5784-5789

28. Lombard C, Nagarkatti M, Nagarkatti P (2007) CB2 cannabinoid receptor agonist, JWH-015, triggers apoptosis in immune cells: 
potential role for $\mathrm{CB} 2$-selective ligands as immunosuppressive agents. Clin Immunol 122:259-270

29. Guzman M (2005) Effects on cell viability. Handb Exp Pharmacol 168:627-642

30. Oz M (2006) Receptor-independent actions of cannabinoids on cell membranes: focus on endocannabinoids. Pharmacol Ther 111:114-144

31. Patsos HA, Hicks DJ, Dobson RR, Greenhough A, Woodman N, Lane JD, Williams AC, Paraskeva C (2005) The endogenous cannabinoid, anandamide, induces cell death in colorectal carcinoma cells: a possible role for cyclooxygenase 2. Gut 54:1741-1750

32. Bisogno T, Cascio MG, Saha B, Mahadevan A, Urbani P, Minassi A, Appendino G, Saturnino C, Martin B, Razdan R, Di Marzo V (2006) Development of the first potent and specific inhibitors of endocannabinoid biosynthesis. Biochim Biophys Acta 1761:205-212

33. Garcia SB, Barros LT, Turatti A, Martinello F, Modiano P, Ribeiro-Silva A, Vespucio MV, Uyemura SA (2006) The anti- obesity agent Orlistat is associated to increase in colonic preneoplastic markers in rats treated with a chemical carcinogen. Cancer Lett 240:221-224

34. Di Marzo V, Izzo AA (2006) Endocannabinoid overactivity and intestinal inflammation. Gut 55:1373-1376

35. Kim R (2005) Recent advances in understanding the cell death pathways activated by anticancer therapy. Cancer 103: $1551-1560$

36. Vandenabeele P, Vanden Berghe T, Festjens N (2006) Caspase inhibitors promote alternative cell death pathways. Sci STKE 2006:pe44

37. Nathke I (2006) Cytoskeleton out of the cupboard: colon cancer and cytoskeletal changes induced by loss of APC. Nat Rev Cancer 6:967-974

38. Takahashi M, Wakabayashi K (2004) Gene mutations and altered gene expression in azoxymethane-induced colon carcinogenesis in rodents. Cancer Sci 95:475-480 